\title{
Increasing photovoltaic panel power through water cooling technique
}

\author{
Calebe A. Matias ${ }^{1}$, Licínio M. Santos ${ }^{1}$, Aylton J. Alves ${ }^{1}$, Wesley P. Calixto ${ }^{1,2}$
}

\begin{abstract}
This paper presents the development of a cooling apparatus using water in a commercial photovoltaic panel in order to analyze the increased efficiency through decreased operating temperature. The system enables the application of reuse water flow, at ambient temperature, over the front surface of photovoltaic (PV) panel and is composed of an inclined plane support, a perforated aluminum profile and a water gutter. A luminaire was specially developed to simulate the solar radiation over the module under test in a closed room, free from the influence of external climatic conditions, to carry out the repetition of the experiment in controlled situations. The first case study was published at EEEIC2016 conference where the panel was submitted to different rates of water flow, from 1 $\mathrm{L} / \mathrm{min}$ to $4 \mathrm{~L} / \mathrm{min}$. In the test conditions without cooling apparatus, the panel reached about $70^{\circ} \mathrm{C}$ and produced approximately $63 \mathrm{Wh}$. With the cooling apparatus with water flow rate of $2 \mathrm{~L} / \mathrm{min}$, the module reached about $50^{\circ} \mathrm{C}$ and produced approximately $77 \mathrm{Wh}$. However, it has been observed that this water flow was overestimated. A second case study was carried out in order to perform the threshold between the flow and the energy produced. The best ratio was flow of $0.6 \mathrm{~L} / \mathrm{min}$ and net energy of $77.41 \mathrm{Wh}$. Gain of $22.69 \%$ compared to the panel without the cooling system.
\end{abstract}

Index Terms - efficiency increase, increasing of the electrical performance, photovoltaic panel, water cooling.

\section{INTRODUCTION}

$\mathrm{A}$ LTHOUGH abundant on Earth, solar energy for electricity production is still little used. This problem stems from factors such as low efficiency in energy conversion, which can be influenced by external agents as solar radiation and temperature, and the high cost of PV panels [1].

The electrical characteristics of photovoltaic cells can be changed due to intrinsic and extrinsic factors. Some factors are resulting from the manufacturing process and the material

The authors would like to thank Coordination for the Improvement of Higher Education Personnel (Capes), the National Counsel of Technological and Science Development (CNPq) Call CNPq-SETEC/MEC No. 17/2014, project 468544/2014-3 and Research Support Foundation of Goias State (FAPEG) for financial support research and scholarships.

C. A. Matias $\{1\}$, calebeabrenhosa@gmail.com

L. M. Santos $\{1\}$, liciniomoraes@gmail.com

A. J. Alves $\{1\}$, aylton.alves@ifg.edu.br

W. P. Calixto $\{1,2\}$, wpcalixto@ieee.org

1 Experimental and Technological Research and Study Group (NExT), Federal Institute of Goias (IFG), Goiânia, Brazil.

2 School of Electrical, Mechanical and Computer Engineering, Federal University of Goias (UFG), Goiânia, Brasil. used, and others are environmental factors such as solar radiation and ambient temperature [2]. Increasing the operating temperature of the PV panel leads, in particular, to the reduction in open circuit voltage $\left(V_{o c}\right)$ and a slight increase in short circuit current $\left(I_{s c}\right)$ which does not compensate for the loss caused by the reduction of voltage, therefore there is a clear loss of power and loss of power conversion efficiency $(\eta)$ [3]. The Fig. 1 shows the Power versus Voltage $(P \times V)$ curves for different operating temperatures, demonstrating the maximum power point drop and the voltage drop due to the temperature increase in the panel [4].

Hybrid systems, photovoltaic/thermal (PV/T), can be used to circumvent the problem of high operating temperature of the panel, for there is a gain in the electrical and thermal efficiency compared to individual systems [5]. This model uses a fluid, usually air, as references [5]-[7], or water, as references [8]-[10], in order to reduce the operating temperature of the panel, transferring heat to the used fluid [11]. The increased electrical efficiency in PV/T systems can reduce the payback period of the investment and also increase the life of the system, which contributes to the growth of economic feasibility for implementation of this type of system and encourages the generation of electricity by this source [1], [12].

This work aims to develop a cooling apparatus of a photovoltaic panel applying reuse water at ambient temperature and analyze the efficiency gains in electricity conversion when the panel is under different rates of water

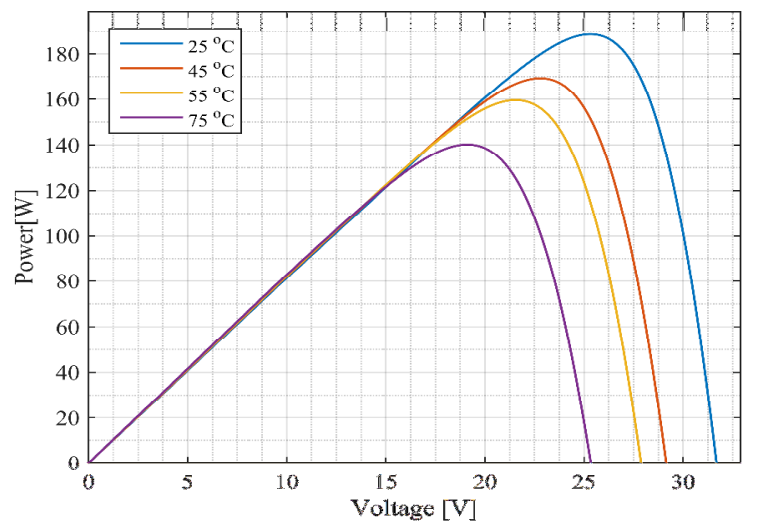

Fig. 1. Dependence of the Photovoltaic power output on panel operating temperature. 
flow and was published at EEEIC2016 conference [13]. This method consists of applying water on the front surface of the panel in order to remove the maximum amount of heat, as references [8]-[10].

Preliminary studies will be performed a quantitative comparison of the increase in power generated, using the apparatus, when the panel is under different rates of water flow ( $1 \mathrm{~L} / \mathrm{min}, 2 \mathrm{~L} / \mathrm{min}, 3 \mathrm{~L} / \mathrm{min}$ and $4 \mathrm{~L} / \mathrm{min}$ ), as reference [13]. An original experiment, second case study, was carried out varying the flow rate from $1 \mathrm{~L} / \mathrm{min}$ to $0.125 \mathrm{~L} / \mathrm{min}$, since the flow observed in case study 1 was overestimated.

The power conversion efficiency of photovoltaic systems is defined as the ratio of the generated electric power by the total power incident over the panel:

$$
\eta=\frac{V_{m} \times I_{m}}{G \times A}
$$

where $V_{m}$ and $I_{m}$ are respectively the maximum voltage and maximum output current, $G$ is the incident solar radiation on the photovoltaic device and $A$ is the area of the PV panel [14].

The percentage of improved efficiency from the PV panel is given by:

$\alpha=\frac{\eta_{m} \times \eta}{\eta} \times 100$

Where $\eta_{m}$ and $\eta$ are, respectively, the efficiency of the modified module and the efficiency of the original module [15].

\section{Methodology}

A photovoltaic panel is cooled using water at ambient temperature to enhance the voltage and thereby increase the power generated by the panel.

\section{A. Materials}

The set of devices used to cool the PV panel consist of a luminaire capable of simulating solar radiation conditions; a water tank, which will supply water through gravitational action; a $140 \mathrm{~W}$ photovoltaic panel, where will be verified the effect of the temperature in power generation; temperature sensors to measure the ambient and the panel temperature; a flow sensor for monitoring the amount of water delivered to the PV panel; a valve to control the water flow; a maximum power point tracker (MPPT) device to extract the maximum power supplied by the panel integrated with a communication device, which will receive all the data and will provide it to a computer from serial link RS-232; a computer for data analysis.

The diagram depicted in Fig. 2 represents the used system, where $i$ ) is the luminaire, $i i$ ) is the water tank, $i i i)$ is the water valve, $i v$ ) is the water flow sensor, $v$ ) is the water input on the photovoltaic panel, vi) is the water output, vii) is the MPPT device and viii) is the computer.

The experiment was conducted in the city of Goiânia, Brazil, in a room, protected from external climatic conditions, where is installed.

A luminaire capable of simulating solar radiation was used aiming at providing stable and constant irradiance throughout the experimental procedure to ensure that the same conditions are repeatable. This step was adopted in order to standardize the irradiance conditions.

LM35 sensors was used to measure the ambient temperature and the PV panel temperature. DS18B20 sensors measured the inlet and outlet water temperature.

The photovoltaic panel was installed on an inclined supporting structure, which allows water runoff through gravitational force.

The Fig. 3 shows the apparatus developed, where: 1 is the built luminaire capable of simulating solar radiation, 2 is the

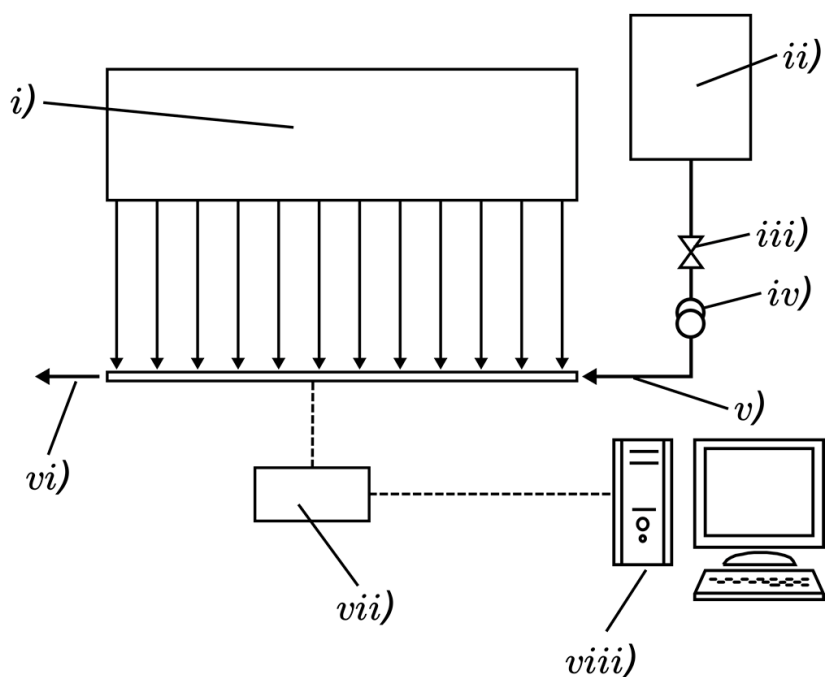

Fig. 2. Operating diagram of the system.

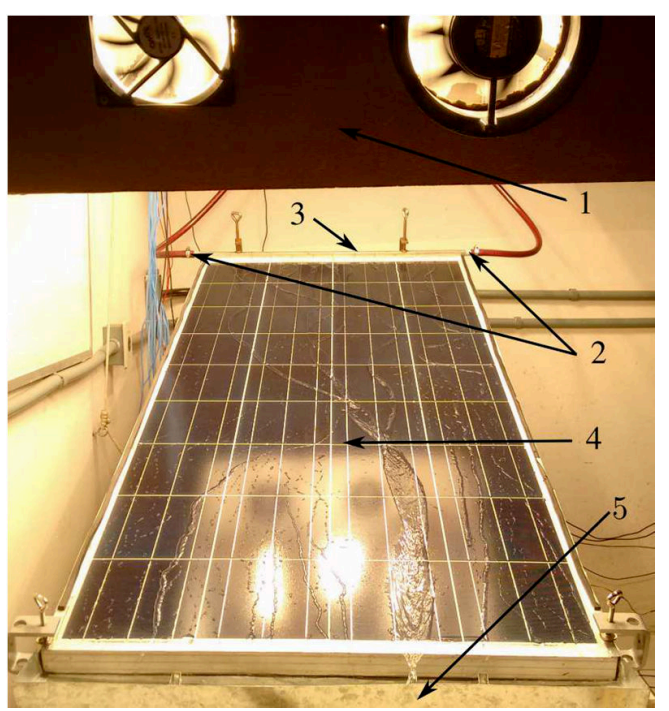

Fig. 3. Developed laboratory bench.

water inlet, 3 is the perforated metal profile for distribution of water over the module, 4 is the PV module and 5 is the water outlet gutter.

\section{B. Data Acquisition}

The simulated solar radiation was fixed at $800 \mathrm{~W} / \mathrm{m}^{2}$ for all the tests. 
The photovoltaic panel was subjected to four different rates of water flow ( $1 \mathrm{~L} / \mathrm{min}, 2 \mathrm{~L} / \mathrm{min}, 3 \mathrm{~L} / \mathrm{min}$ and $4 \mathrm{~L} / \mathrm{min}$ ) in order to establish which provide the highest net increase of power. The second case study was carried out varying the flow rate from $1 \mathrm{~L} / \mathrm{min}$ to $0.125 \mathrm{~L} / \mathrm{min}$.

The first case study was conducted at an interval of 30 minutes in which the values of voltage, current, power, ambient temperature and photovoltaic panel operating temperature were stored in the data logger.

\section{RESULTS}

\section{A. Case Study 1}

Fig. 4 indicates that the water flow rate on the photovoltaic panel influences the generated power.

Fig. 5 presents a wide variation in panel temperature during the experiment. The temperature sensor is positioned in the center of the panel, where it was observed higher values.

It is observed in Fig. 4 and Fig. 5 as the instantaneous power without cooling system decrease when the panel temperature increase. The initial panel temperature is equal the ambient temperature, approximately $25^{\circ} \mathrm{C}$, and it gets about

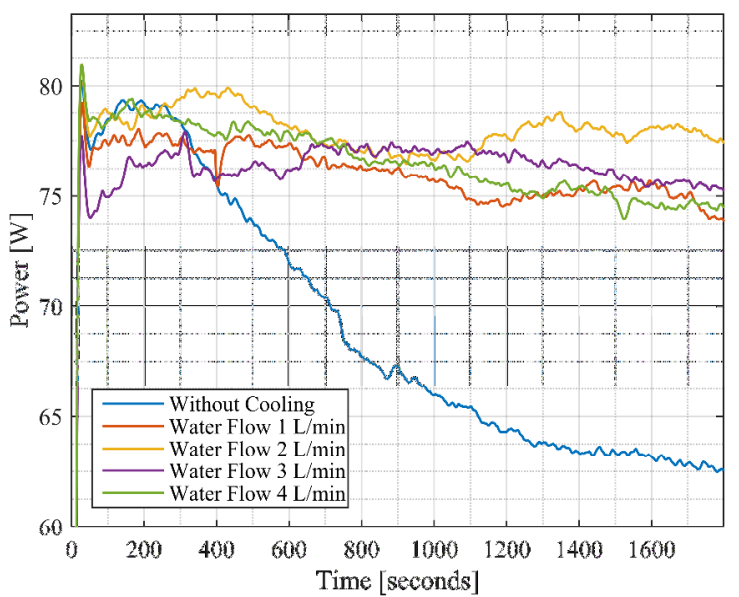

Fig. 4. Effect of water flow rate in the generation of the maximum power.

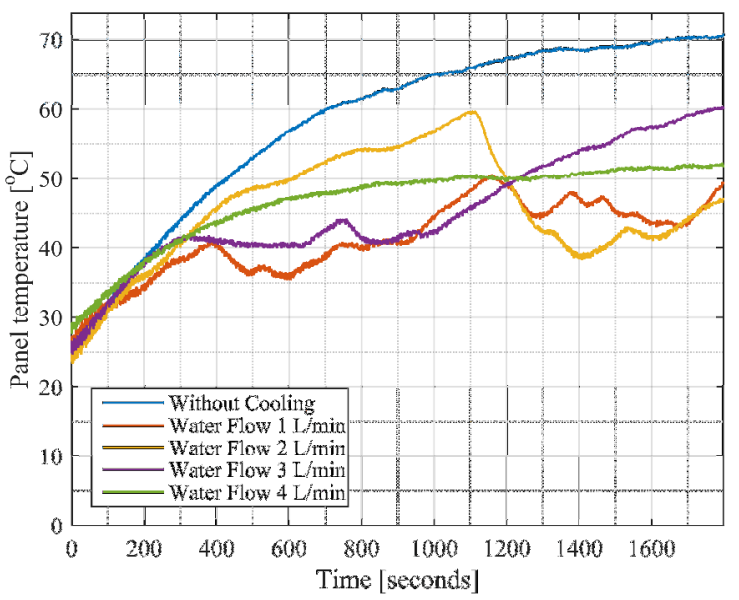

Fig. 5. Effect of water flow rate in the panel temperature. $70^{\circ} \mathrm{C}$ without cooling system. When applied the water flow on the photovoltaic panel its temperature drops and the instantaneous power rise.

It was expected that higher water flow rates leads to enhancement of the power production, but it is not observed in Fig. 4. The data shows that the water flow rate of $2 \mathrm{~L} / \mathrm{min}$ generates more power than others.

Fig. 6 depicts the randomness of the water flow on the panel surface. The distribution of temperature is not the same in all points of the panel, which may vary suddenly the path taken by the water, this may explain why the water flow rate of 4 $\mathrm{L} / \mathrm{min}$, for example, in a few moments, it was less effective for improving panel efficiency than lower flow rates. Table I

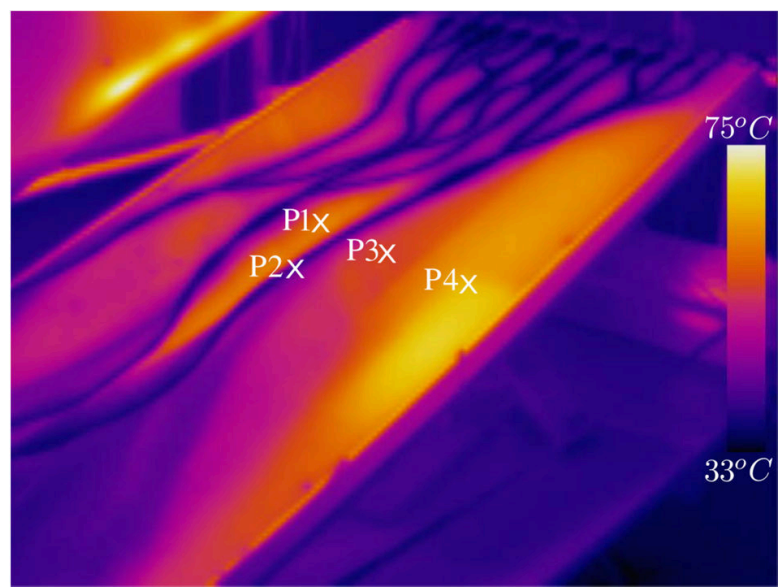

Fig. 6. Thermal image of the photovoltaic panel when the water flow is 2 $\mathrm{L} / \mathrm{min}$

TABLE I

TEMPERATURES INDICATED BY THE THERMAL IMAGER.

\begin{tabular}{cc}
\hline Markers & Temperature $\left({ }^{\circ} \mathrm{C}\right)$ \\
\hline P1 & 58.0 \\
$P 2$ & 41.8 \\
P3 & 49.6 \\
P4 & 68.2 \\
\hline \hline
\end{tabular}

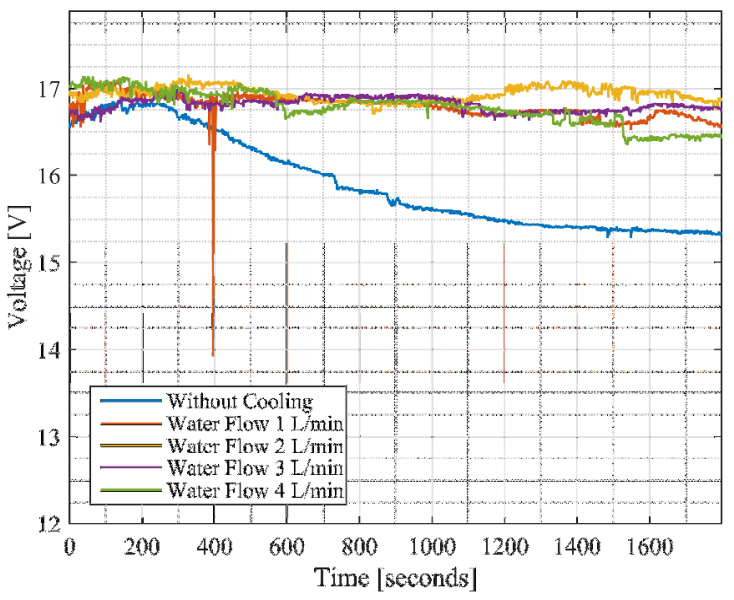

Fig. 7. Effect of water flow rate in the voltage produced. 
indicates the temperature provided by a thermal imager and a huge difference in temperature at nearby points.

Panel work operating temperature declines the voltage and therefore induces the decrease of power. Fig. 7 shows the influence of temperature on the voltage produced by the photovoltaic panel.

The power, depicted in Fig. 4, follows the voltage change, for the current keeps almost constant, approximately 4.7 A, during the experiment, observed in Fig. 8.

The total energy produced using different water flow rates can be seen in Table II. The water flow corresponding to

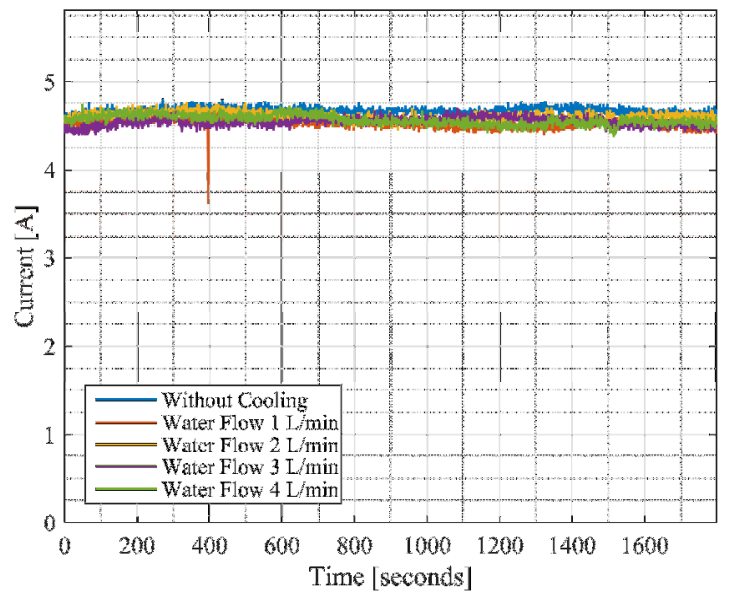

Fig. 8. Effect of water flow rate in the current produced.

$2 \mathrm{~L} / \mathrm{min}$ showed the highest gain efficiency, $22.90 \%$, compared to the test done without the cooling apparatus.

\section{B. Case Study 2}

In order to overcome the problem of heating, as shown in
TABLE II

EFFICIENCY GAIN OF THE PV PANEL WITH THE COOLING SYSTEM.

\begin{tabular}{ccc}
\hline \hline Water Flow (L/min) & Energy (Wh) & Efficiency Gain (\%) \\
\hline Without & 63.09 & - \\
1 & 74.81 & 18.57 \\
2 & 77.54 & 22.90 \\
3 & 75.62 & 19.86 \\
4 & 75.32 & 19.38 \\
\hline \hline
\end{tabular}

Fig. 6, a solenoid valve has been inserted into the system to obstruct the passage of water for a certain period of time with the purpose of ensuring that the water flows through the entire surface of the panel.

It is observed in case study 1 that the volume of water applied in the panel is exaggerated, since the difference between the generated potencies is not large.

A new experiment was performed by setting the water flow rate to $1 \mathrm{~L} / \mathrm{min}$ and activating the solenoid valve at different time intervals.

The tests were performed under the same conditions as in the case study 1 .

The panel was exposed to the luminaire for 30 minutes without the cooling system. After this period the solenoid valve was switched on for 10 minutes at a constant flow rate of $1 \mathrm{~L} / \mathrm{min}$. In order to vary the flow rate of the water, the valve was acted in different time intervals (Ton $=$ on and Toff $=$ off). The valve opening and closing time is given in seconds and is shown in Table III. $1 \mathrm{~L} / \mathrm{min}$ is the reference and other values are expressed as a percentage.

The interval $T_{0}-T_{1}$ shown in Fig. 9 is 30 minutes and the interval $T_{1}-T_{2}$ is 10 minutes.

Figure 9 shows the data obtained from this experiment, where the first graph shows the power generated by the panel, the second shows the panel temperature, the third shows the
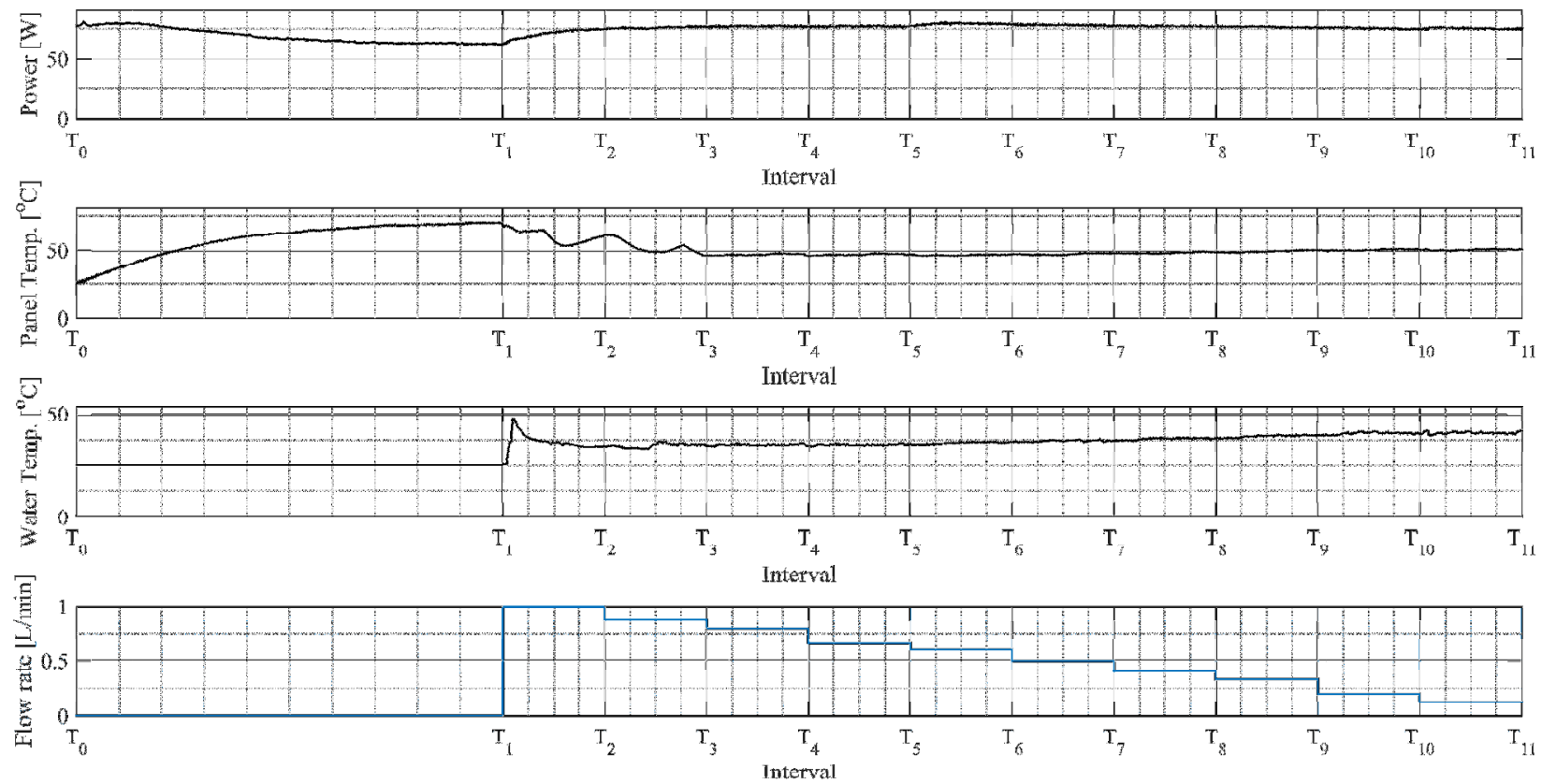

Fig. 9. Data from the case study 2. 


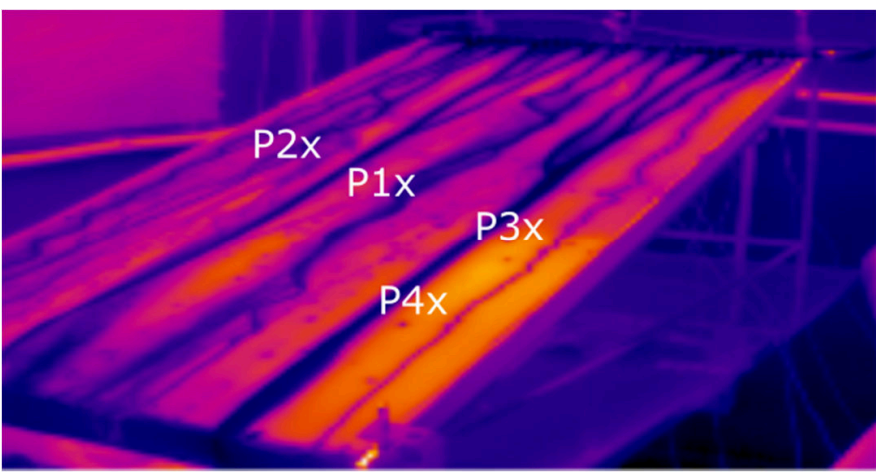

a) Thermal image of the photovoltaic panel when the water flow is $0.6 \mathrm{~L} / \mathrm{min}$. Fig. 10. Bench structure.

water outlet temperature and the fourth shows the average water flow rate applied to the panel.

Fig. 10 (a) shows the thermal image of the PV panel. As can be seen, the control through the solenoid valve, identified in Fig. 10 (b) by the number 1 , forces the water to always take a different path cooling most of the photovoltaic panel.

Table IV shows the temperature markers of Fig. 10 (a).

TABLE IV

TEMPERATURES INDICATED BY THE THERMAL IMAGER.

\begin{tabular}{cc} 
Markers & Temperature $\left({ }^{\circ} \mathrm{C}\right)$ \\
\hline P1 & 42.3 \\
$P 2$ & 44.6 \\
$P 3$ & 51.8 \\
P4 & 59.5 \\
\hline \hline
\end{tabular}

Considering the steady state of the power and temperature in the interval between $T_{0}-T_{1}$, that is, in the last 10 minutes, a comparison is made between the energy generated in each time interval and the gain of the efficiency with respect to the energy produced by the panel without cooling during the stability period. The energy was calculated in relation to the average produced during the stability period. The water flow is in relation to $1 \mathrm{~L} / \mathrm{min}$. The efficiency gain is shown in Table V.

\section{Data management}

It was observed that the amount of water applied on the panel was overestimated, as higher flows did not generate more energy. Another problem observed was the stagnation of the water path. Some regions remained at higher temperatures.

In case study 2 the water flow rate varies from $1 \mathrm{~L} / \mathrm{min}$ to $0.125 \mathrm{~L} / \mathrm{min}$. The flow control was performed through the opening and closing period of a solenoid valve. The flow that provided the highest net energy, Table $\mathrm{V}$, was $0.6 \mathrm{~L} / \mathrm{min}$, showing an efficiency gain of $24.8 \%$. This flow had a level of efficiency gain similar to case 1 , since the path traveled by the water varied over the whole area of the photovoltaic panel.

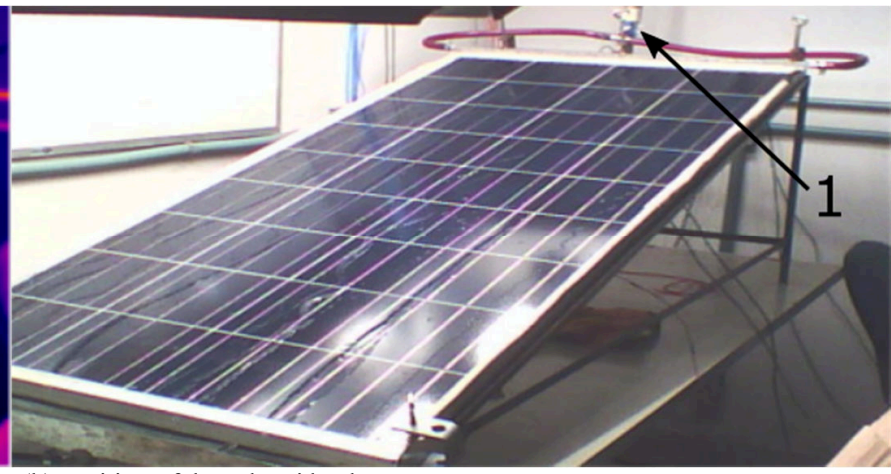

(b) Position of the solenoid valve.

TABLE V

EFFICIENCY GAIN OF THE PV PANEL WITH THE COOLING SY STEM.

\begin{tabular}{ccc}
\hline Water Flow (\%) & Energy $(\mathrm{Wh})$ & Efficiency Gain $(\%)$ \\
\hline Without & 63.09 & - \\
100 & 71.12 & 12.72 \\
87.5 & 75.65 & 19.90 \\
80 & 76.67 & 21.52 \\
66 & 76.68 & 21.54 \\
60 & 78.74 & 24.80 \\
50 & 77.77 & 23.27 \\
40 & 76.85 & 21.81 \\
33 & 76.23 & 20.82 \\
20 & 75.20 & 19.19 \\
12.5 & 75.05 & 18.96 \\
\hline \hline
\end{tabular}

The best case observed was $60 \%$ of water flow rate: $0.6 \mathrm{~L} / \mathrm{min}$.

The reservoir of water is located in the room where the experiment was performed. The tank is at a height of 1.5 meters from the water inlet of the panel. In order to quantify the energy spent in a real system, was proposed a hypothetical situation in which the reservoir would be 6 meters height distant from the capture and treatment system of reuse water installed in facilities of the institution.

An analysis was performed to determine the amount of energy needed by a pumping system to elevate the water to a height of approximately 6 meters. It is desirable that the used pump has the lowest power possible, since the flow rate values and head height satisfies the proposed pumping system in order to achieve a more efficient system, with higher yields and that does not compromise achieved power gain using the cooling apparatus.

The suggested pump is the Etanorm 050-032-125.1220V, single-phase with $139 \mathrm{~mm}$ rotor, and a $370 \mathrm{~W}$ motor. This set was obtained by analysis of the technical datasheet using a flow rate of $10 \mathrm{~m}^{3} / \mathrm{h}$ and head height of 8 mca.

Table VI shows the amount of water required to cool the panel for 1 hour when subjected to several different flow rates. It was also shown the power required to transport this amount of water using the same pump, but with different operating 
time. The net energy gain, calculated by the difference between the energy generated with the cooling technique and the energy expended in the water transport, is shown in the last column.

Table VI shows that the best water flow rate to cool the photovoltaic panel is $0.6 \mathrm{~L} / \mathrm{min}$, because it provided the greatest net energy. There was an increase of $22.69 \%$ efficiency, when the temperature was $70^{\circ} \mathrm{C}$ on the panel, which may result in reducing the payback period of investment. Another effect of the implementation of this apparatus is to produce the same amount of energy in a smaller space than a conventional photovoltaic plant.

TABLE VI

NET EFFICIENCY GAIN OF THE PV PANEL WITH COOLING SYSTEM

\begin{tabular}{ccccc}
\hline \hline $\begin{array}{c}\text { Water } \\
\text { Flow }\end{array}$ & $\begin{array}{c}\text { Generated } \\
\text { energy (Wh) }\end{array}$ & $\begin{array}{c}\text { Pump } \\
\text { energy } \\
\text { (Wh) }\end{array}$ & $\begin{array}{c}\text { Net } \\
\text { energy } \\
(\text { Wh })\end{array}$ & $\begin{array}{c}\text { Efficiency } \\
\text { gain }(\%)\end{array}$ \\
\hline Without & 63.09 & - & - & - \\
4 & 75.32 & 8.88 & 66.44 & 5.30 \\
3 & 75.62 & 6.66 & 68.96 & 9.30 \\
2 & 77.54 & 4.44 & 73.1 & 15.86 \\
1 & 74.81 & 2.22 & 72.59 & 15.05 \\
0.875 & 75.65 & 1.94 & 73.71 & 16.83 \\
0.8 & 76.67 & 1.77 & 74.9 & 18.71 \\
0.66 & 76.68 & 1.46 & 75.22 & 19.22 \\
0.6 & 78.74 & 1.33 & 77.41 & 22.69 \\
0.5 & 77.77 & 1.11 & 76.66 & 21.50 \\
0.4 & 76.85 & 0.888 & 75.96 & 20.40 \\
0.33 & 76.23 & 0.73 & 75.5 & 19.67 \\
0.2 & 75.20 & 0.44 & 74.76 & 18.49 \\
0.125 & 75.05 & 0.27 & 74.78 & 18.52 \\
\hline \hline
\end{tabular}

The cost of the water used is virtually null, given that the industries should dispose of wastewater effluent properly in rivers, lakes or oceans, according to local regulations, after the treatment of solid waste in water treatment plants.

This apparatus therefore can be implemented in industries where there is this kind of water supply, encouraging the generation of photovoltaic electricity.

\section{CONCLUSION}

This work shows that decreasing the panel operating temperature, when subjected to cooling apparatus, is the factor responsible for the increase of the voltage and consequently the increase of the amount of energy produced. In initial conditions, without cooling apparatus, the photovoltaic panel produced $63.09 \mathrm{Wh}$, for $70^{\circ} \mathrm{C}$ on the panel, and after using a water flow rate of $0.6 \mathrm{~L} / \mathrm{min}$ it produced around $78.74 \mathrm{Wh}$, for about $50^{\circ} \mathrm{C}$ on the panel, a gain of $24.80 \%$. A hypothetical case of water transport was implemented to simulate the amount of energy needed to cool the panel for 1 hour. Then the comparative analysis of the increase in efficiency using the apparatus reveals that the water flow of $0.6 \mathrm{~L} / \mathrm{min}$ on the front surface of the panel provides the highest net power increase,

\section{$22.69 \%$.}

The apparatus, consequently can be implemented in industrial facilities, where there is reuse water potential, in order to increase the amount of energy produced and/or reduce the payback period of the investment. The results show that the water distribution system, under the PV panel can be improved to optimize the efficiency of the water flow used.

\section{REFERENCES}

[1] H. A. Hussien, A. H. Numan, and A. R. Abdulmunem, "Improving of the photovoltaic/thermal system performance using water cooling technique," IOP Conf. Series: Materials Science and Engineering, vol. 78, no. $012020,2015$.

[2] M. Sharma, K. Bansal, and D. Buddhi, "Real time data acquisition system for performance analysis of modified pv module and derivation of cooling coefficients of electrical parameters," Procedia Computer Science, vol. 48, pp. 582-588, 2015.

[3] S. Dubey, J. N. Sarvaiya, and B. Seshadri, "Temperature dependent photovoltaic (pv) efficiency and its effect on pv production in the world - a review," Energy Procedia, vol. 33, pp. 311-321, 2013.

[4] E. Skoplaki and J. Palyvos, "On the temperature dependence of photovoltaic module electrical performance: A review of efficiency/power correlations," Solar Energy, vol. 83, pp. 614-624, 2009.

[5] S. C. Solanki, S. Dubey, and A. Tiwari, "Indoor simulation and testing of photovoltaic thermal (pv/t) air collectors," Applied Energy, vol. 86, pp. 2421-2428, 2009

[6] S. Dubey, G. S. Sandhu, and G. N. Tiwari, "Analytical expression for electrical efficiency of pv/t hybrid air collector," Applied Energy, vol. 86, pp. 697-705, 2009.

[7] S. Dubey, S. C. Solanki, and A. Tiwari, "Energy and exergy analysis of pv/t air collectors connected in series," Energy and Buildings, vol. 41, pp. 863-870, 2009

[8] Y. M. Irwana et al., "Indoor test performance of pv panel through water cooling method," Energy Procedia, vol. 79, pp. 604-611, 2015.

[9] V. Eveloya, P. Rodgers, and S. Bojanampati, "Enhancement of photovoltaic solar module performance for power generation in the middle east," 28th ieee semi-therm symposium, pp. 87-97, 2012.

[10] D. Kim, D. H. Kim, S. Bhattarai, and J.-H. Oh, "Simulation and model validation of the surface cooling system for improving the power of a photovoltaic module," Journal of Solar Energy Engineering, vol. 133, no. $041012,2011$.

[11] H. Zondag, "Flat-plate pv-thermal collectors and systems: A review," Renewable and Sustainable Energy Reviews, vol. 12, pp. 891-959, 2008.

[12] J. Ji, J. Lu, T. Chow, W. He, and G. Pei, “A sensitivity study of a hybrid photovoltaic/thermal water-heating system with natural circulation," Applied Energy, vol. 84, pp. 222-237, 2007.

[13] Matias, C. A.; Santos, L. M.; Alves, A. J. and Calixto, W. P. Electrical performance evaluation of PV panel through water cooling technique. (EEEIC) IEEE 16th International Conference on Environment and Electrical Engineering, 2016. DOI: 10.1109/EEEIC.2016.7555643.

[14] M. Chandrasekar and T. Senthilkumar, "Experimental demonstration of enhanced solar energy utilization in flat pv (photovoltaic) modules cooled by heat spreaders in conjunction with cotton wick structures," Energy, vol. 90, pp. 1401-1410, 2015.

[15] T. Chow, "A review on photovoltaic/thermal hybrid solar technology," Applied Energy, vol. 87, pp. 365-379, 2009. 


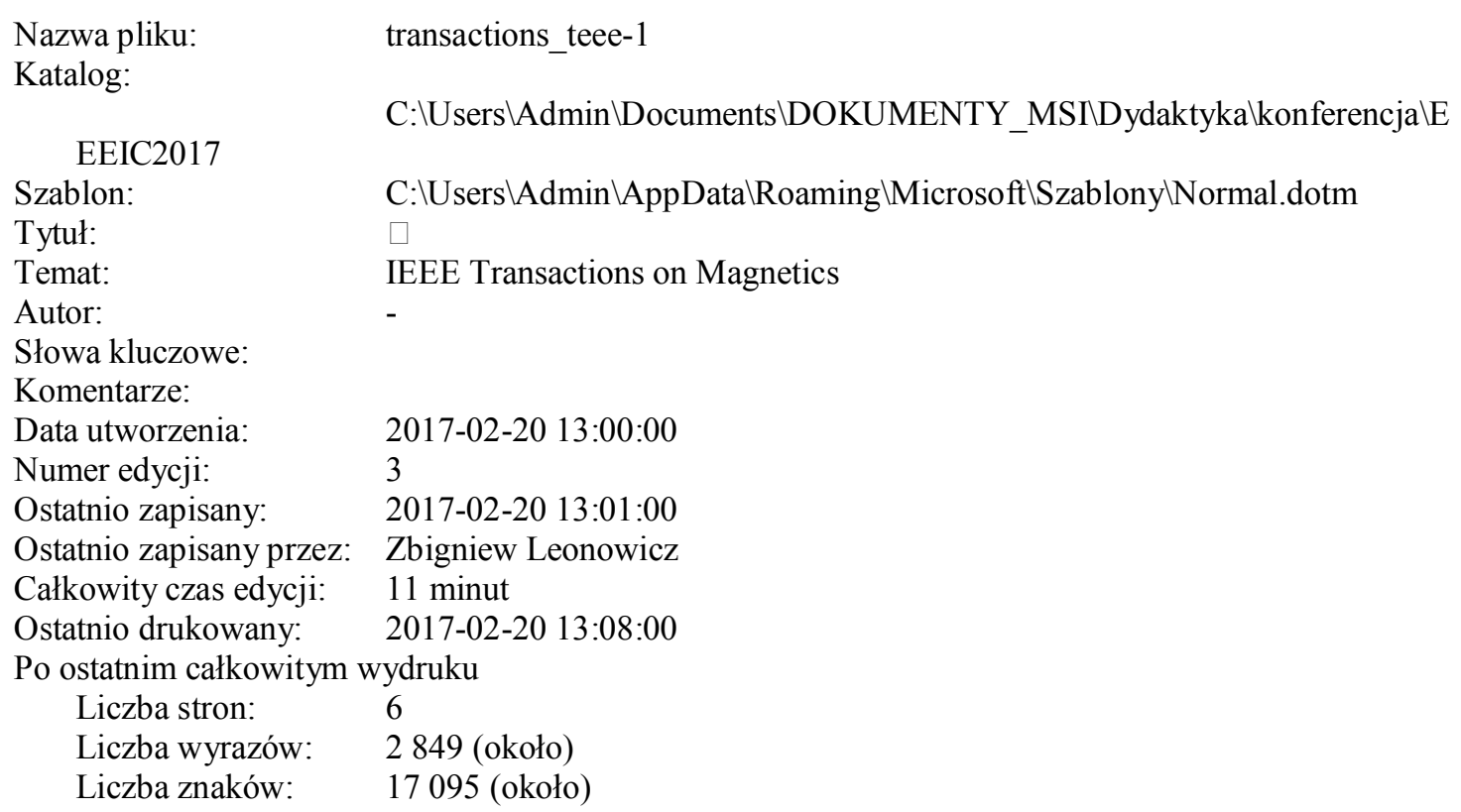

